\title{
Mulheres das ciências médicas e da saúde e publicações brasileiras sobre Covid-19
}

\author{
Women of medical and health sciences and Brazilian publications on \\ Covid-19
}

Estela M. L. Aquino $\mathbf{1 , 3}$, Luisa Maria Diele-Viegass,3, Flávia Bulegon Pilecco ${ }^{\mathbf{3}, 4}$, Ana Paula Reis $\mathbf{1 , 3}$, Greice Maria de Souza Menezes ${ }^{\mathbf{1 , 3}}$

DOI: 10.1590/0103-11042021E105

\begin{abstract}
RESUMO Apesar do aumento histórico da participação feminina na produção científica brasileira, reconfigurações domésticas e laborais para o controle da Covid-19 podem estar reduzindo a produtividade das mulheres cientistas. A pesquisa GenCovid-Br objetivou traçar um panorama da participação feminina nos artigos sobre Covid-19 das ciências médicas e da saúde, disponibilizados no PubMed, com ao menos um autor de filiação brasileira. Das 1.013 publicações até 14 de agosto de 2020, 6,1\% foram escritas exclusivamente por mulheres; $17,2 \%$, exclusivamente por homens; grupos mistos respondem por $31,1 \%$ com liderança feminina, e 45,6\% com liderança masculina. As mulheres participam mais de artigos com primeira autoria feminina (50,1\% vs 35,6\% nos liderados por homens). Nos artigos de áreas da Medicina Clínica, em que as mulheres são maioria, ocorre menos participação de autoras, o que também acontece em publicações resultantes de colaborações internacionais. Os presentes resultados indicam a possibilidade de ampliação de desigualdades de gênero prévias durante a pandemia de Covid-19. Novos estudos devem aprofundar a investigação sobre a magnitude e os determinantes desse fenômeno, incluindo análises temporais. As políticas institucionais devem considerar as iniquidades de gênero nas avaliações acadêmicas, prevenindo impactos futuros nas carreiras das mulheres, em particular, das jovens pesquisadoras envolvidas na reprodução social.
\end{abstract}

PALAVRAS-CHAVE Gênero e saúde. Ciências da saúde. Sexismo. Transversalidade de gênero. Covid-19.

\footnotetext{
1 Universidade Federal da Bahia (UFBA), Instituto de Saúde Coletiva (ISC) Salvador (BA), Brasil. estela@ufba.br

2 Universidade Federal de Alagoas (UFAL) - Maceió $(A L)$, Brasil.

3 Rede CoVida - Ciência, Informação e Solidariedade - Salvador (BA), Brasil.

4 Universidade Federal de Minas Gerais (UFMG)

- Belo Horizonte (MG), Brasil.
}

\begin{abstract}
Despite the increasing historical participation of women in Brazilian scientific production, domestic and labor reconfiguration for the control of the Covid-19 pandemic is likely to reduce women scientists' productivity. The GenCovid-Br Research aimed to outline a panorama of female production in Covid-19 papers in medical and health sciences, available in PubMed, with at least one author with Brazilian affiliation. From the 1,013 publications by August 14, 2020, 6.1\% were written exclusively by women, 17.2\% exclusively by men, $31.1 \%$ were mixed with female leadership, and $45.6 \%$ were mixed with male leadership. Women participated in more papers led by women (50.1\% vs. $35.6 \%$ in those led by men). Papers in Clinical Medicine, where female researchers are predominant, have fewer female authors, occurring in publications resulting from international collaborations. Our results point to the possible expansion of previous gender inequalities during the Covid-19 pandemic. New studies should deepen the investigation of the magnitude and determinants of such phenomenon, including temporal analyses. Institutional policies must consider gender inequalities in academic assessments, preventing future impacts on women's careers, particularly young researchers involved in social reproduction.
\end{abstract}

KEYWORDS Gender and health. Health sciences. Sexism. Gender mainstreaming. Covid-19. 


\section{Introdução}

A produção científica sobre a Covid-19 tem aumentado, exponencialmente, na busca por respostas para o controle da pandemia. Entretanto, tem suscitado interesse na literatura internacional uma aparente redução da produtividade das mulheres cientistas, decorrente do aumento das demandas domésticas e da diminuição do apoio social para o cuidado da família, especialmente das crianças, na vigência de medidas de distanciamento social1-8. Isso estaria revertendo uma tendência histórica de incremento da participação feminina nas ciências ${ }^{9,10}$. Em 2017, um relatório da Elsevier ${ }^{11}$ havia evidenciado que a proporção de mulheres entre pesquisadores e inventores estava aumentando em todos os 12 países e regiões avaliados, ao longo do tempo. O Brasil e a Dinamarca tinham apresentado o maior crescimento desse indicador no período. Todavia, mantinham-se as desigualdades de gênero na ciência, que variavam muito entre países e áreas do conhecimento. No entanto, em geral, registrava-se menor presença feminina nos artigos publicados, principalmente como primeira e última autorias.

As mulheres brasileiras, durante muito tempo, estiveram ausentes ou pouco representadas nos espaços acadêmicos ${ }^{9}$. Esse panorama começou a se modificar nas últimas décadas, quando se intensificou a escolarização feminina ${ }^{12}$ e sua entrada, inclusive, em áreas tradicionalmente masculinas - como medicina, odontologia e mesmo nas engenharias e ciências exatas 9 . Uma das consequências desse processo tem sido o aumento consistente da participação das mulheres em atividades de pesquisa. Em 2010, elas se equipararam aos homens entre os pesquisadores cadastrados no Diretório de Grupos de Pesquisa da Plataforma Lattes do Conselho Nacional de Desenvolvimento Científico e Tecnológico $(\mathrm{CNPq})^{\mathbf{1 3}, \mathbf{1 4}}$. Apesar disso, as mulheres utilizavam menos as bolsas no exterior, como, por exemplo, no Programa Ciências sem Fronteiras ${ }^{15}$, e mantinha-se a desvantagem feminina no acesso às Bolsas de Produtividade em Pesquisa ${ }^{16}$ e a posições de prestígio, como, por exemplo, a inexpressiva participação na coordenação de Institutos Nacionais de Ciência e Tecnologia (INCT/ $\mathrm{CNPq})^{16}$ e a entrada minoritária na Academia Brasileira de Ciências ${ }^{17}$.

As ciências da saúde têm grande peso na produção científica brasileira, como resultado de um crescimento histórico significativo; e as mulheres constituem maioria dos pesquisadores, ainda que haja uma variação entre as subáreas que a compõem ${ }^{\mathbf{1 8}}$. Segundo dados obtidos no Painel Lattes (CNPq), em 2016 , elas correspondiam a $60,2 \%$ do total de 20.444 doutores envolvidos em atividades de pesquisa e ensino das ciências de saúde ${ }^{19}$. Caberia, então, perguntar: qual a sua participação na produção científica em resposta ao maior desafio mundial nos últimos cem anos, especialmente considerando aquelas pesquisadoras diretamente envolvidas com a produção de conhecimentos biomédicos e da saúde?

Essa indagação motivou a realização da Pesquisa GenCovid-Br (GenCovid-Br Research), cujos primeiros resultados são aqui apresentados. Este artigo pretendeu traçar um panorama da participação das mulheres nas publicações científicas brasileiras sobre Covid-19, com enfoque nas ciências médicas e da saúde.

\section{Material e métodos}

O corpus deste estudo reúne todas as referências sobre Covid-19, que se encontram disponíveis no portal PubMed da U.S. National Library of Medicine (NLM), no período de $1^{\circ}$ de dezembro de 2019 a 14 de agosto de 2020. Esse portal tem como principal componente a base de dados Medline (responsável por 83,9\% das referências indexadas), maior base de referências e citações da literatura biomédica do mundo. Inclui, adicionalmente, artigos ahead of print, textos completos disponibilizados 
no PubMed Central, manuscritos de autores financiados pelos National Institutes of Health (NIH) e livros disponíveis no National Center for Biotechnology Information (https://www. nlm.nih.gov/bsd/difference.html). Foram incluídas todas as referências com, pelo menos, um autor afiliado a uma instituição brasileira, independentemente do idioma e do tipo de publicação. Para isso, foi definida a seguinte estratégia de busca: ("Covid-19" OR "2019 novel coronavirus infection" OR "Covid19" OR "coronavirus disease 2019" OR "coronavirus disease-19” OR "2019-nCoV disease" OR "2019 novel coronavirus disease" OR " $2019-\mathrm{nCoV}$ infection" OR "severe acute respiratory syndrome coronavirus 2" OR "Wuhan coronavirus" OR "Wuhan seafood market pneumonia virus" OR "Covid19 virus" OR "Covid-19 virus" OR "coronavirus disease 2019 virus" OR "SarsCoV-2" OR "Sars2” OR "2019-nCoV” OR "2019 novel coronavirus") AND ("Brazil" [Affiliation] OR "Brasil" [Affiliation]).

Para a extração e filtragem dos artigos, foi usado o pacote easyPubMed ${ }^{20}$, no ambiente estatístico R 4.0.221. Em seguida, foi feita uma busca manual em sites da internet para recuperar as autorias identificadas apenas com iniciais do primeiro nome do autor. $\mathrm{O}$ gênero dos autores foi codificado com o uso do pacote gender ${ }^{22}$. Para a classificação das áreas de conhecimento das ciências médicas e da saúde, adotou-se o esquema mais usado internacionalmente, proposto pela Organisation for Economic Co-operation and Development (OECD) ${ }^{23}$. Este abrange cinco grandes categorias: "Medicina básica" (inclui nove subáreas, tais como imunologia, farmacologia, bioquímica e neurociências); "Medicina clínica" (inclui 27 especialidades clínicas); "Ciências da Saúde" (inclui 14 categorias como epidemiologia, ciências do cuidado em saúde - compreendendo administração hospitalar e financiamento do cuidado em saúde -, política e serviços de saúde, doenças infecciosas, ética médica, enfermagem, nutrição e dietética, saúde ocupacional, parasitologia, saúde pública e ambiental, ciências biomédicas sociais - incluindo planejamento familiar, saúde sexual, psico-oncologia, efeitos políticos e sociais da pesquisa biomédica -, ciências do esporte, abuso de substâncias e medicina tropical); "Biotecnologia da saúde"; e "Outras ciências médicas". Para a codificação, foram considerados os seguintes campos: filiação institucional do primeiro autor, título da revista de publicação e palavras-chave do artigo. Havendo discordância entre os campos, ou dúvida a respeito da área predominante, foi examinado o currículo do primeiro autor para estabelecê-la. Por fim, a partir da instituição de filiação, foram extraídas as informações sobre os países dos pesquisadores, agrupados em continentes.

Na presente análise, os artigos foram divididos em quatro grupos, de acordo com a composição de gênero e posição de mulheres e homens na primeira autoria: compostos exclusivamente por mulheres e exclusivamente por homens, e artigos de autoria mista com mulheres como primeiras autoras e com homens como primeiros autores.

Para cada grupo, foram descritas frequências relativas e absolutas de artigos publicados e mensurada a participação de mulheres na autoria (como primeira autora e em qualquer posição); foram calculadas medidas de tendência central e de dispersão (média, desvio padrão, mediana, intervalos interquartílicos e amplitude) referentes ao número de autores dos artigos; e elaborados gráficos e um mapa de frequência representando as colaborações internacionais. Essas análises foram efetuadas nos pacotes dplyr ${ }^{24}$, ggplot2 ${ }^{25}$ e maps $^{26}$.

\section{Resultados}

Em 14 de agosto de 2020, 40.888 referências sobre Covid-19 foram identificadas, publicadas desde o início da pandemia, em dezembro de 2019. Com a sintaxe proposta, foram localizados no PubMed 1.046 artigos, que tinham ao menos um autor vinculado a instituições brasileiras. Após a exclusão de 33 de outras áreas 
científicas, 1.013 foram classificados como integrantes das ciências médicas e da saúde, os quais tinham 7.902 autores envolvidos.

Os três primeiros artigos, com pelo menos um autor afiliado a uma instituição brasileira, foram registrados em 18 de março de 2020, todos com composição mista de gênero. Entretanto, destes, somente um com liderança feminina ${ }^{27}$; e os outros dois ${ }^{\mathbf{2 8}, 29}$, com liderança masculina e, ademais, atribuída a autores estrangeiros. Foram muito poucos os artigos com apenas um autor, 17 escritos por mulheres, e 46 (quase o triplo), por homens.

Considerando-se os 1.013 artigos publicados entre março e agosto, constata-se uma grande variação na composição de gênero da autoria dos artigos: $6,1 \%$ foram escritos exclusivamente por mulheres; $17,2 \%$, exclusivamente por homens; $31,1 \%$ têm autoria mista e primeira autora mulher; e $45,6 \%$ têm autoria mista e primeiro autor homem (gráfico 1).

Gráfico 1. Distribuição proporcional dos autores e artigos sobre Covid-19 da área de ciências médicas e da saúde, segundo composição de gênero do grupo de autores e posição na autoria - março a agosto de 2020.

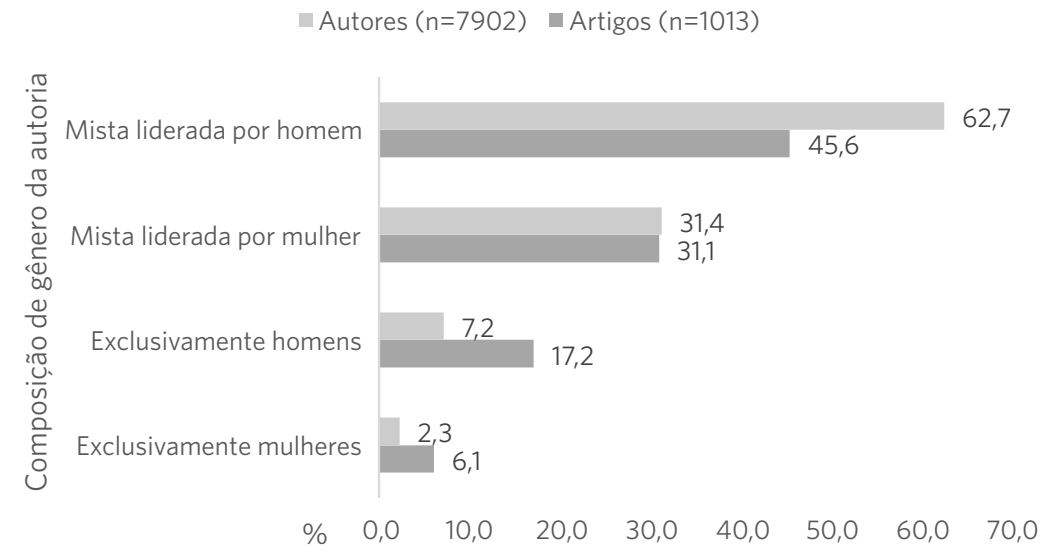

Fonte: Elaboração própria.

Se contemplada a distribuição nos quatro grupos de todos os 7.902 autores, nota-se que as diferenças se ampliam. Os artigos com composição mista reúnem o maior número de autores, porém são aqueles liderados por homens os que têm o maior percentual $(62,7 \%)$ (gráfico 1). Isso se confirma na análise quantitativa do número de autores que integram cada grupo e sua distribuição média (tabela 1). 
Tabela 1. Número médio e mediano de autores (intervalo interquartílico, desvio padrão e amplitude de variação) de artigos sobre Covid-19 da área de ciências médicas e da saúde, segundo composição de gênero do grupo de autores e posição na autoria - fevereiro a agosto de 2020

\begin{tabular}{|c|c|c|c|c|c|}
\hline \multirow[b]{2}{*}{$\begin{array}{l}\text { Medidas de tendências central e de } \\
\text { dispersão }\end{array}$} & \multicolumn{5}{|c|}{ Composição de gênero da autoria ${ }^{1}$} \\
\hline & $\begin{array}{r}\text { Exclusivamente } \\
\text { mulheres }(n=178)\end{array}$ & $\begin{array}{r}\text { Exclusivamente } \\
\text { homens }(n=569)\end{array}$ & $\begin{array}{l}\text { Mista liderada por } \\
\text { mulher }(n=2.507)\end{array}$ & $\begin{array}{l}\text { Mista liderada por } \\
\text { homem }(n=4.674)\end{array}$ & Total $(n=7.968)$ \\
\hline Mediana (Intervalo Interquartílico) & $2(1-4)$ & $3(1-4)$ & $6(4-9)$ & $6(4-10)$ & $5(1-8)$ \\
\hline Média (Desvio Padrão) & $2,9(2,0)$ & $3,3(3,1)$ & $8,0(7,6)$ & $10,2(12,3)$ & $7,9(9,9)$ \\
\hline Amplitude (valor mínimo e máximo) & $1-11$ & $1-24$ & $2-55$ & $2-120$ & $1-120$ \\
\hline
\end{tabular}

Fonte: Elaboração própria.

'Houve 23 observações perdidas na variável composição de gênero da autoria.

Os artigos de autoria exclusiva feminina ou masculina têm, ambos, menos autores do que os de autoria mista; e, ainda que seus valores medianos sejam próximos, a média e a amplitude dos artigos escritos somente por homens são maiores, com um número máximo de autores superior. Quando analisados os grupos mistos, ainda que as medianas sejam equivalentes, aqueles liderados por uma mulher têm, no máximo, 55 autores, enquanto os liderados por homens alcançam o valor máximo de 155 autores.
No conjunto dos 1.013 artigos, as mulheres representam apenas $39,2 \%$ dos autores (tabela 2). A participação feminina é maior em artigos liderados por mulheres (50,1\%) do que naqueles com homens como primeiros autores (35,6\%). A participação delas cresce em ambas as categorias quando analisados somente os artigos que têm apenas brasileiros ( $57,6 \%$ e $40,2 \%$ respectivamente) em relação aos artigos que incluem estrangeiros (44,3\% e $33,0 \%$ respectivamente).

Tabela 2. Participação relativa (\%) das mulheres na autoria de artigos sobre Covid-19 da área de ciências médicas e da saúde, segundo composição de gênero do grupo de autores e posição na autoria - fevereiro a agosto de 2020

\begin{tabular}{|c|c|c|c|c|c|}
\hline \multirow[b]{3}{*}{ Nacionalidade dos autores } & \multicolumn{5}{|c|}{ Composição da autoria ${ }^{1}$} \\
\hline & $\begin{array}{r}\text { Exclusivamente } \\
\text { mulheres }\end{array}$ & $\begin{array}{r}\text { Exclusivamente } \\
\text { homens }\end{array}$ & $\begin{array}{r}\text { Mista liderada por } \\
\text { mulher }\end{array}$ & $\begin{array}{r}\text { Mista liderada por } \\
\text { homem }\end{array}$ & Total \\
\hline & $\%(n)$ & $\%(n)$ & $\%(n)$ & $\%(n)$ & $\%(n)$ \\
\hline Autores exclusivamente brasileiros & $100,0 \%(n=140)$ & $-(n=301)$ & $57,6 \%(n=1101)$ & $40,2 \%(n=1678)$ & $45,0 \%(n=3220)$ \\
\hline Autores brasileiros e estrangeiros & $100,0 \%(n=38)$ & $-(n=268)$ & $44,3 \%(1406)$ & $33,0 \%(n=2996)$ & $35,2 \%(n=4715)$ \\
\hline Total & $100,0 \%(n=178)$ & $-(n=569)$ & $50,1 \%(2507)$ & $35,6 \%(n=4674)$ & $39,2 \%(n=7928)$ \\
\hline
\end{tabular}

Fonte: Elaboração própria.

1Houve 23 observações perdidas na variável composição de gênero do grupo de autores.

Nota: $O$ ' $n$ ' corresponde à soma de mulheres e homens de cada grupo no estrato.

A menor colaboração internacional das mulheres é evidenciada pelo predomínio de artigos mistos liderados por homens sobre as demais categorias de autoria no panorama mundial (figura 1). 
Figura 1. Número de autores de publicações científicas brasileiras sobre Covid-19 da área de ciências médicas e da saúde, que envolvem colaboradores estrangeiros, segundo continente de origem e composição de gênero do grupo de autores - fevereiro a agosto de 2020

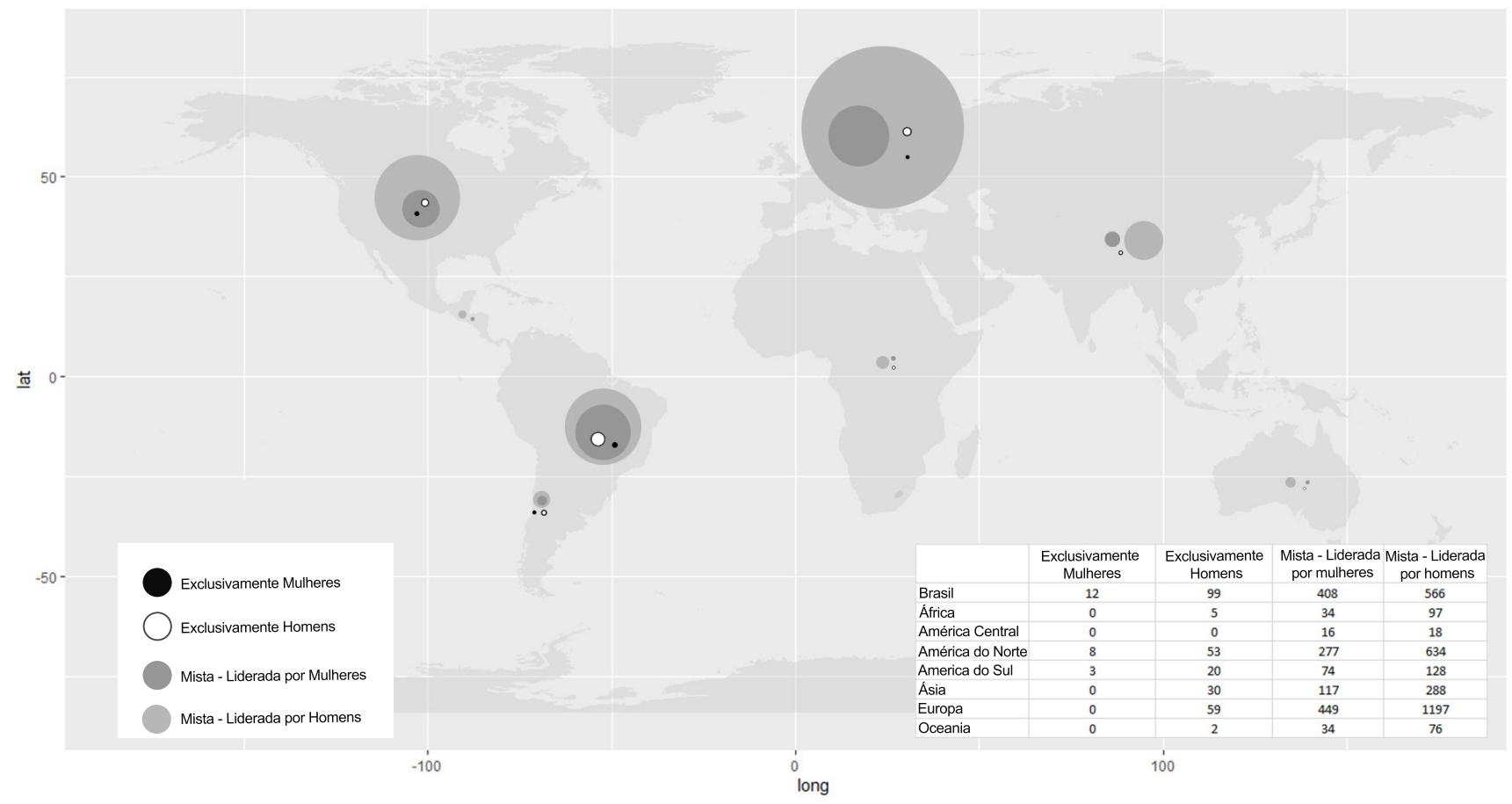

Fonte: Elaboração própria.

De forma geral, a maioria das colaborações internacionais ocorre em artigos mistos. As principais conexões acontecem com a Europa e a América do Norte. Cabe assinalar que, entre os artigos mistos liderados por homens, os autores europeus e norte-americanos são, inclusive, mais numerosos que os colaboradores brasileiros. O número de autores europeus nessa categoria, em específico, representa mais que o dobro do de brasileiros. Entre os artigos mistos de autoria feminina, no entanto, apenas os de colaboradores europeus superam os de brasileiros. Por fim, chamam a atenção também as conexões com a Ásia e com a América Latina, proporcionalmente muito mais frequentes em artigos mistos liderados por homens do que nos liderados por mulheres.
A análise da participação feminina nas áreas das ciências médicas e da saúde (gráfico $2 a$ $e 2 b)$ permite identificar que as maiores diferenças estão na medicina clínica, seja em qualquer posição entre os autores (36\%), seja, principalmente, na primeira autoria (33\%). A biotecnologia também tem proporção baixa de autoras, ainda que elas sejam equivalentes aos homens na primeira autoria. Nas ciências da saúde, o percentual de mulheres é de $44 \%$ dos autores em qualquer posição de autoria e equivale ao encontrado na medicina básica. Contudo, a proporção de primeira autoria feminina é menor (respectivamente, $40 \%$ e 48\%). $\mathrm{Na}$ biotecnologia, o número de mulheres e homens como primeiros autores é baixo e se equivale. 
Gráfico 2. Distribuição de autores e participação feminina na autoria de artigos brasileiros sobre Covid-19, segundo gênero e áreas do conhecimento das ciências da saúde

$2 a$ - Autores em qualquer posição de autoria

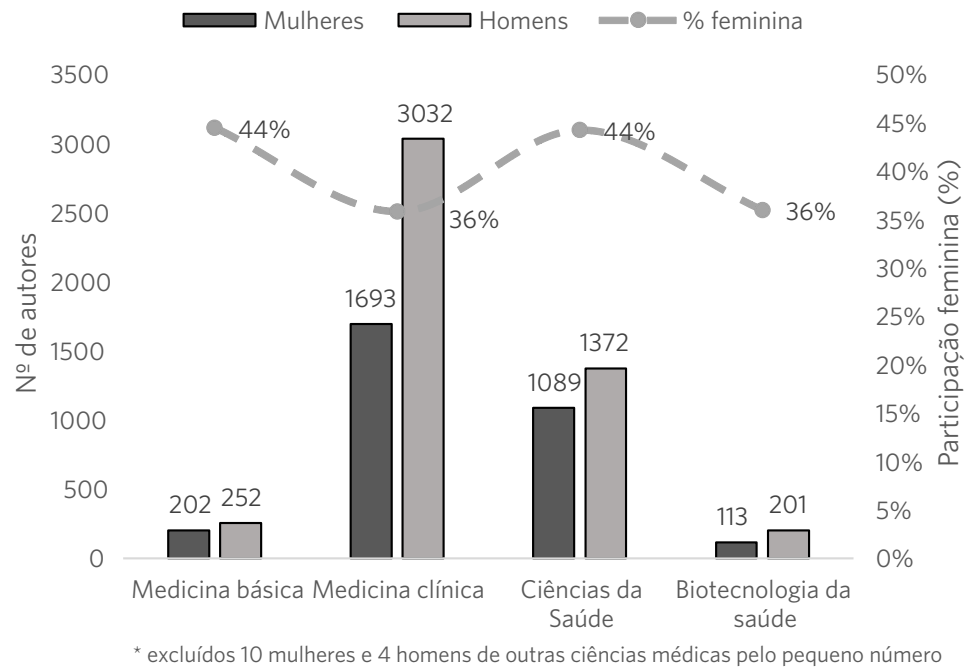

$2 b-$ Autores na primeira autoria

$\rightleftarrows$ Mulheres $\longleftarrow$ Homens - - \% feminina

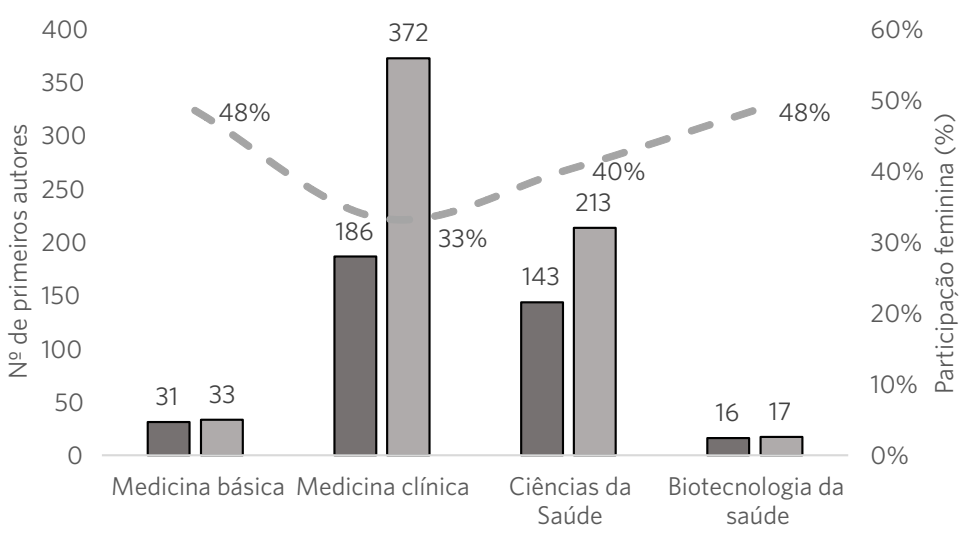

* excluídos 1 homem e 1 mulher de outras ciências médicas pelo pequeno número

Fonte: Elaboração própria.

\section{Discussão}

Os resultados apresentados são convergentes com a literatura internacional ${ }^{2-4,7,30-34}$ e nacional ${ }^{33,35}$. Ademais, evidenciam uma disparidade de gênero na produção científica analisada sobre a Covid-19. Relativamente aos homens, as mulheres têm menor participação no conjunto dos artigos e como primeiras autoras, tal como constatado em outros trabalhos 3,32,34,35.
Um dos limites do presente estudo, na etapa atual da pesquisa, é não dispor ainda de análises temporais que permitam identificar se isso constitui uma tendência de aumento das publicações de autoria masculina, e/ou decréscimo de publicações femininas, durante a pandemia. De qualquer modo, fica claro que há menor proporção de artigos de autoria exclusivamente feminina, e elas lideram menos artigos de autoria mista, em uma área do conhecimento 
em que são maioria no Brasil18,19. Os artigos com uma única autoria - muito poucos - são escritos majoritariamente por homens, como é apontado na literatura ${ }^{2}$.

Outro limite a ser comentado decorre do uso do Pubmed como única fonte dos artigos. Isso pode ter excluído parte da produção de outras áreas, em especial das ciências humanas e sociais, sobre saúde, publicadas em periódicos especializados que não integram a base utilizada. É possível que isso tenha influenciado a distribuição por áreas do conhecimento, devendo ser investigado em estudos futuros. Contudo, pode-se supor que a magnitude da proporção de mulheres no total de publicações não se altere substancialmente, já que se trata da base mais abrangente de referências sobre a Covid19. Esse é um debate relevante que merece estudos posteriores e está sendo contemplado nas novas análises da Pesquisa GenCovid-Br. De todo modo, o estudo teve como ponto forte sua grande amplitude. Essa foi também assegurada pelo inexpressivo número de perdas de registros e da recuperação cuidadosa de informações sobre o nome de autores e área do conhecimento.

Entre os achados que instigam novas análises e estudos, situam-se as condições em que as mulheres têm menor participação: quando o artigo tem liderança masculina, inclui autores estrangeiros e/ou a primeira autoria é da área de medicina clínica.

$\mathrm{O}$ androcentrismo influencia a atuação acadêmica em todos os níveis; da escolha das áreas do conhecimento aos mecanismos de acesso e progressão na carreira, inclusive com a ocupação de postos, em uma estrutura profundamente hierarquizada ${ }^{36}$. Essa hierarquia se impõe na dinâmica da distribuição de poder e de prestígio, incluindo a coordenação de projetos de pesquisa e a autoria dos trabalhos acadêmicos. No modelo androcêntrico, o cientista ideal confere prioridade ao trabalho e tem poucos interesses ou responsabilidades de outras esferas, inclusive a família ${ }^{37}$. A excelência acadêmica implica longas horas de trabalho de performance sustentada - incompatível com os ciclos de vida das mulheres e com o seu papel na reprodução social ${ }^{37,38}$. Estudos apontam que a primeira posição de autoria tem sido ocupada por pesquisadores mais jovens e no início de suas carreiras. Para as mulheres, essa época corresponde ao período reproduti$\mathrm{vo}^{31}$, dificultando seu engajamento profissional ou implicando o adiamento da maternidade. No entanto, a performance sustentada atinge outros momentos de vulnerabilidade, como as situações de crise, doença, envelhecimento e morte de familiares e amigos. Nesse sentido, isso pode afetar tanto as mulheres quanto os homens, em diferentes fases da vida. Na pandemia de Covid-19, essas situações proliferam e atingem particularmente a elas, que são as mais envolvidas com o cuidado de idosos e doentes.

Um aspecto que não pode ser minimizado diz respeito à potencial exacerbação de vieses de gênero ${ }^{4,39}$ na avaliação das publicações, em decorrência do aumento exponencial da produção científica e da aceleração dos mecanismos de revisão por pares (fast-track peer review) nas revistas científicas, sob o imperativo da circulação imediata de conhecimentos que embasem ações de controle. Uma possível questão a ser investigada é se há disparidades de gênero na publicação efetiva dos artigos em preprint.

A menor participação das mulheres em parcerias internacionais pode expressar dinâmicas específicas das áreas científicas, o que merece futuramente ser estudado. Todavia, é consistente com a constatação prévia de um menor acesso delas às bolsas no exterior e a iniciativas de consórcios e estudos multicêntricos entre países ${ }^{11}$.

Outro aspecto que pode contribuir para acentuar as disparidades de gênero na produção científica sobre Covid-19, especialmente no Brasil, marcado por desigualdades sociais, relaciona-se com os rearranjos nas tarefas familiares e profissionais impostos pela pandemia. As medidas de distanciamento social, adotadas por praticamente todos os países, resultaram na transferência do trabalho profissional para o ambiente doméstico, em um 
contexto de aumento das demandas familiares, em decorrência do fechamento de escolas e redução do apoio social para o cuidado de crianças, idosos e enfermos - inclusive para aqueles em isolamento pela Covid-19, que não necessitaram de hospitalização ${ }^{\mathbf{4 0}}$. Isso tem tido repercussão direta no tempo dispensado ao trabalho doméstico. As horas dedicadas ao cuidado da família, incluindo a supervisão das tarefas escolares das crianças, são desigualmente distribuídas, impondo sobrecarga às mulheres, fenômeno amplamente documentado na pandemia $\mathbf{4}^{\mathbf{4} 31,38,41}$.

Essa nova configuração, marcada pela confluência do trabalho profissional e doméstico no mesmo espaço, ocupado pela família - 24 horas 7 dias na semana -, pode ser incompatível com o processo de produção acadêmica, que requer tempo e concentração por longas horas ininterruptas ${ }^{37}$. Normas estruturantes de gênero mantêm a atribuição às mulheres da responsabilidade majoritária (quando não exclusiva) pelo cuidado da família e de adultos dependentes $\mathbf{4}^{\mathbf{4} \mathbf{4 2}}$. A Covid-19 parece impor às pesquisadoras uma intensificação de funções tradicionais de gênero, que podem ter impacto no seu desempenho acadêmico - em especial mulheres com filhos pequenos ${ }^{33}$. Isso ocorre mesmo entre casais com alta escolaridade e/ou do âmbito acadêmico ${ }^{13,43}$. O esforço de conciliação entre demandas do trabalho e da família implica decisões, nem sempre fáceis, que, em geral, sequer se colocam para os homens, para os quais parece que já está definido que sejam priorizadas as exigências do trabalho acadêmico. Para as mulheres pesquisadoras, no entanto, essa escolha está sempre colocada, e o chamado conflito trabalho-família é fartamente documentado na literatura prévia à pandemia.

\section{Considerações finais}

A Pesquisa GenCovid-Br (GenCovid-Br Research) dispõe de uma base rica que permite novas e mais aprofundadas análises sobre o tema. Nesse sentido, dada a heterogeneidade da conformação das disciplinas da área de ciências médicas e da saúde, pretende-se prosseguir as análises deste corpus, considerando a participação das mulheres nas subáreas de atuação. Do mesmo modo, objetiva-se verificar a evolução da produção ao longo dos meses para identificar tendências temporais e seus determinantes. Estudos futuros devem ser feitos para analisar os efeitos de longo prazo da pandemia de Covid-19 nas trajetórias acadêmicas das mulheres ${ }^{2,3}$, especialmente daquelas com filhos pequenos e em início de carreira.

Novas investigações também devem, na medida do possível, adotar uma perspectiva interseccional, incluindo, além do gênero, outras categorias de análise que são apontadas na literatura como marcadores de desigualdades, como a raça/cor dos pesquisadores ${ }^{33}$ e o estágio em que se encontram nas suas carreiras profissionais ${ }^{2,3}$. Igualmente, deve-se considerar, em novos estudos, as desigualdades regionais na distribuição de recursos para pesquisa, especialmente quando o vínculo é com instituição fora dos grandes centros e do eixo Rio de Janeiro-São Paulo. As iniquidades de gênero no campo científico são também fortemente influenciadas pelos arranjos familiares, a experiência de parentalidade e a idade dos filhos ${ }^{4,31,33}$.

É imprescindível que as iniquidades de gênero na produtividade cientifica, em tempos de Covid-19, sejam consideradas nos sistemas de avaliação e progressão nas carreiras das mulheres cientistas ${ }^{4}$. As equipes editoriais devem monitorar a sub-representação de mulheres nas suas composições, assim como políticas científicas devem ser adotadas para maior inclusão da diversidade de grupos de pesquisadores/as.

O distanciamento social e o confinamento podem servir não apenas para reduzir a transmissão do Sars-CoV-2 e prevenir a Covid-19. No entanto, podem também representar uma oportunidade sem precedentes para repensar práticas e modos de vida, inclusive no âmbito acadêmico. É preciso priorizar o bem-estar 
coletivo sobre a produtividade e reconhecer que a performance sustentada no trabalho acadêmico se mantém com base nas iniquidades sociais. Para que pesquisadores e pesquisadoras produzam conhecimentos, muitas pessoas desempenham o trabalho técnico e administrativo. No Brasil, as mulheres negras constituem grande parte da força de trabalho que sustenta as instituições científicas, como secretárias, funcionárias administrativas, pessoal de limpeza etc. ${ }^{44,45}$. Em contrapartida, elas representam pouco menos de $1 \%$ do total de orientadores de doutorado e dos bolsistas de produtividade do CNPq (0,8\% em 2015) ${ }^{\mathbf{4 6}, 47}$. No âmbito doméstico, diante da participação minoritária dos homens, são as trabalhadoras domésticas, em sua maioria negras, que frequentemente liberam cientistas e pesquisadoras do cuidado da casa e da família ${ }^{48}$. Durante a pandemia, esse apoio se reduziu, expondo as desigualdades sociais que parecem se acentuar durante a crise sanitária.

É tempo, portanto, de refletir sobre mudanças necessárias para superar a lógica da produtividade a qualquer preço e instituir uma ética do cuidado, tal como defendem pesquisadoras catalãs em seu belo artigo 'Academia in the Time of COVID-19: Towards an Ethics of Care'49.
Um aspecto crucial relaciona-se aos temas priorizados e àqueles não explorados como decorrência da sub-representação da contribuição de mulheres na sua diversidade. Em tempos 'normais', já se alertava para o fato de que a ciência não pode prescindir da capacidade intelectual das mulheres, que representam uma parte expressiva da comunidade acadêmica. Na pandemia de Covid-19, isso pode significar a renúncia a respostas das quais, urgentemente, a humanidade precisa.

\section{Colaboradoras}

Aquino EML (0000-0002-8204-1249)* e Diele-Viegas LM (0000-0002-9225-4678)* conceberam a ideia do estudo e a estrutura inicial do manuscrito, e dividem a primeira autoria. Diele-Viegas LM realizou a coleta, visualização e análise dos dados, com a colaboração de Aquino EML e Pilecco FB (00000001-8316-8797)*. Todas as autoras, Aquino EML, Diele-Viegas LM, Pilecco FB, Reis AP (0000-0002-6750-0187)* e Menezes GMS (0000-0002-8393-2545)* realizaram a revisão da literatura, interpretaram os resultados, escreveram e aprovaram o manuscrito principal. 


\section{Referências}

1. Cardel MI, Dean N, Montoya-Williams D. Preventing a Secondary Epidemic of Lost Early Career Scientists: Effects of COVID-19 Pandemic on Women with Children. Ann Am Thorac Soc. 2020; 17(11):136-170.

2. Amano-Patiño N, Faraglia E, Giannitsarou C, et al. The Unequal Effects of Covid-19 on Economists' Research Productivity. 2020. [acesso em 2020 mar 20]. Disponível em: https://www.repository.cam. ac.uk/bitstream/handle/1810/310888/cwpe2038. pdf? sequence $=1 \&$ isAllowed $=y$.

3. Andersen JP, Nielsen MW, Simone NL, et al. Meta-Research: COVID-19 medical papers have fewer women first authors than expected. Elife. 2020; (9):e58807.

4. Cui R, Ding H, Zhu F. Gender Inequality in Research Productivity During the COVID-19 Pandemic. 2020. [acesso em 2021 mar 20]. Disponível em: https://papers.ssrn.com/sol3/Data_Integrity_Notice. cfm?abid=3623492.

5. Maas B, Grogan KE, Chirango Y, et al. Academic leaders must support inclusive scientific communities during COVID-19. Nat. Ecol. Evol. 2020; (4):997-998.

6. Muric G, Lerman K, Ferrara E. COVID-19 amplifies gender disparities in research. arXiv preprint arXiv:200606142. 2020. [acesso em 2020 mar 20]. Disponível em: https://arxiv.org/ftp/arxiv/papers/2006/2006.06142.pdf.

7. Viglione G. Are women publishing less during the pandemic? Here's what the data say. Natur. 2020; 581(7809):365-6.

8. Fox CW. The representation of women as authors of submissions to ecology journals during the COVID-19 pandemic. bioRxiv. 2020. [acesso em 2021 mar 20]. Disponível em: https://www.biorxiv.org/content/10 $.1101 / 2020.05 .29 .123455 \mathrm{vl}$.full.pdf.

9. Leta J. As mulheres na ciência brasileira: crescimento, contrastes e um perfil de sucesso. Estud. avanç. 2003; 17(49):271-84.
10. Aquino EM. Gênero e ciência no Brasil: contribuições para pensar a ação política na busca da equidade. In: Heilborn ML, Aquino EM, Barbosa RM, et al., editores. Sexualidade, reprodução e saúde 1. Rio de Janeiro: Editora FGV; 2009. p. 57-72.

11. Elsevier. Gender in the Global Research Landscape: Analysis of Research Performance Through a Gender Lens Across 20 Years, 12 Geographies, and 27 Subject Ares. [acesso em 2020 mar 20]. Disponível em: https://www.elsevier.com/_data/assets/pdf_ file/0008/265661/ElsevierGenderReport_final_for-web.pdf.

12. Beltrão KI, Alves JED. A reversão do hiato de gênero na educação brasileira no século XX. Cad. Pesquisa. 2009; 39(136):125-56.

13. Ferrari LP. Mulheres na Ciência. Revista Expressão. 2019; 8(1):55-59.

14. Conselho Nacional de Desenvolvimento Científico e Tecnológico. Pesquisadores por sexo Plataforma Lattes CNPq. 2015. [acesso em 2020 mar 20]. Disponível em: http://lattes.cnpq.br/web/dgp/pesquisadores-por-sexo.

15. Feltrin RB, Costa JOP, Velho L. Mulheres sem fronteiras? Uma análise da participação das mulheres no Programa Ciência sem Fronteiras da Unicamp: motivações, desafios e impactos na trajetória profissional. Cadernos Pagu. 2016; (48):e164804.

16. Lima BS, Santana Braga ML, Tavares I. Participação das mulheres nas ciências e tecnologias: entre espaços ocupados e lacunas. Revista Gên. 2016; 16(1):1131 .

17. Ferrari NC, Martell R, Okido DH, et al. Geographic and gender diversity in the Brazilian Academy of Sciences. An. Acad. Bras. Cienc. 2018; 90(2):2543-52.

18. Melo HPD, Oliveira AB. A produção científica brasileira no feminino. Cadernos Pagu. 2006; (27):301-31. 
19. Conselho Nacional de Desenvolvimento Científico e Tecnológico. Estatísticas da Base de Currículos da Plataforma Lattes. Brasília, DF: CNPq; 2016. [acesso em 2020 ago 31]. Disponível em: http://estatico.cnpq. br/painelLattes/sexofaixaetaria/.

20. Fantini D. easyPubMed: Search and Retrieve Scientific Publication Records from PubMed. 2019. [acesso em 2020 ago 31]. Disponível em: https://cran.r-project.org/web/packages/easyPubMed/vignettes/getting_started_with_easyPubMed.html.

21. R Core Team. R: A language and environment for statistical computing. [acesso em 2020 mar 30]. Disponível em: http://r.meteo.uni.wroc.pl/web/packages/ dplR/vignettes/intro-dplR.pdf.

22. Blevins C, Mullen L. Jane, John... Leslie? A Historical Method for Algorithmic Gender Prediction. DHQ. 2015; 9(3).

23. Organisation for Economic Co-operation Development. Revised field of science and technology (FOS) classification in the Frascati manual. [acesso em 2020 mar 30]. Disponível em: https://www.oecd.org/science/inno/38235147.pdf.

24. Wickham H, Francois R, Henry L, et al. dplyr: A Grammar of Data Manipulation. R package version1.0.1. Vienna: R Found. Stat. Comput; 2020.

25. Wickham H. ggplot2: elegant graphics for data analysis. Suíça: springer; 2016.

26. Minka T, Deckmyn A. maps: Draw Geographical Maps. R package version 3.3. 02018.

27. Giovanetti M, Benvenuto D, Angeletti S, et al. The first two cases of 2019-nCoV in Italy: Where they come from? J Med Virol. 2020; 92(5):518-21.

28. Benvenuto D, Giovanetti M, Ciccozzi A, et al. The 2019-new coronavirus epidemic: evidence for virus evolution. J Med Virol. 2020;92(4):455-9.

29. Biscayart C, Angeleri P, Lloveras S, et al. The next big threat to global health? 2019 novel coronavirus (2019-
$\mathrm{nCoV}$ ): What advice can we give to travellers?-Interim recommendations January 2020, from the Latin-American society for Travel Medicine (SLAMVI). Travel Med Infect Dis. 2020; (33):101567.

30. Gabster BP, van Daalen K, Dhatt R, et al. Challenges for the female academic during the COVID-19 pandemic. Lancet. 2020; 395(10242):1968-70.

31. Oleschuk M. Gender Equity Considerations for Tenure and Promotion during COVID-19. Can Rev Sociol. 2020; 57(3):502-515.

32. Pinho-Gomes A-C, Peters S, Thompson K, et al. Where are the women? Gender inequalities in COVID-19 research authorship. BMJ Glob. Health. 2020; 5(7):e002922.

33. Staniscuaski F, Kmetzsch L, Soletti RC, et al. Gender, race and parenthood impact academic productivity during the COVID-19 pandemic: from survey to action. Front Psychol. 2020; (12):663252

34. Vincent-Lamarre P, Sugimoto C, Larivière V. The decline of women's research production during the coronavirus pandemic. Nature index. 2020. [acesso em 2021 jul 30]. Disponível em: https://www.natureindex.com/news-blog/decline-women-scientist-research-publishing-production-coronavirus-pandemic.

35. Candido MR, Campos LA. Pandemia reduz submissões de artigos acadêmicos assinados por mulheres. Blog Dados. [acesso em 2021 jul 30]. Disponível em: http://dados.iesp.uerj.br/pandemia-reduz-submissoes-de-mulheres/.

36. Bandeira L. A contribuição da crítica feminista à ciência. Rev. Estud. Fem. 2008; 16(1):207-28.

37. Fox MF. Gender, family characteristics, and publication productivity among scientists. Soc Stud Sci. 2005; 35(1):131-50.

38. Melo HPd, Castilho M. Trabalho reprodutivo no Brasil: quem faz? Rev de Econ. Contemp. 2009; (13):13558. 
39. Goyal L. Let's Focus on Gender Equity. Cell Host \& Microbe. 2020; 27(3):307.

40. Aquino EML, Silveira IH, Pescarini JM, et al. Social distancing measures to control the COVID-19 pandemic: potential impacts and challenges in Brazil. Ciênc. Saúde Colet. 2020; 25(supll): 2423-46.

41. Adams-Prassl A, Boneva T, Golin M, et al. Inequality in the impact of the coronavirus shock: Evidence from real time surveys. IZA Institute of Labor Economics. [acesso em 2021 jul 2]. Disponível em: http:// ftp.iza.org/dp13183.pdf.

42. Minello A. The pandemic and the female academic. Nature. 2020; (17):2020.

43. Schiebinger L, Davies Henderson A, Gilmartin S. Dual-career academic couples: what universities need to know. [acesso em 2021 jul 2]. Disponível em: https:// stanford.app.box.com/s/y5bicy7o3cxwtmgy22iu.

44. Pace ÂF. Afro-brasileiros e racismo institucional: o papel do concurso na democratização de acesso aos cargos públicos. [dissertação]. Seropédica: Universidade Federal Rural do Rio de Janeiro. 2012. 152 p. [acesso em 2021 jul 2]. Disponível em: https://tede. ufrrj.br/jspui/handle/jspui/1498.
45. Viana RR, Tokarski CP. Burocracia Representativa: uma (re) produção de Desigualdades de Gênero e Raça no Setor Público Federal? NAU Social. 2019; 10(19).

46. Lima BS, Santana Braga ML, Tavares I. Participação das mulheres nas ciências e tecnologias: entre espaços ocupados e lacunas. Revista Gên. 2015; 16(1).

47. Silva J. Doutoras professoras negras: o que nos dizem os indicadores oficiais. Perspectiva. 2010; 28(1):19-36.

48. Castro MG. Trabalhadoras domésticas no Brasil. Princípios. 2020; 1(159):126-50.

49. Corbera E, Anguelovski I, Honey-Rosés J, et al. Academia in the Time of COVID-19: Towards an Ethics of Care. Plan. Theory Pract. 2020; 21(6485):1-9.

Recebido em 05/09/2020 Aprovado em 07/06/2021

Conflito de interesses: inexistente

Suporte financeiro: Bolsa de Produtividade em Pesquisa do Conselho Nacional de Desenvolvimento Científico e Tecnológico (CNPq) (Processo no 306295/2017-2) da autora Estela Maria Motta Lima Leão de Aquino 